\title{
Limites e possibilidades do exercício da autonomia nas práticas terapêuticas de modificação corporal e alteração da identidade sexual
}

| 1 Miriam Ventura, ${ }^{2}$ Fermin Roland Schramm |

Resumo: As normas brasileiras condicionam o acesso às modificações corporais para alteração da identidade sexual à confirmação do diagnóstico psiquiátrico de transexualismo transtorno de identidade de gênero ou sexual -, e o acompanhamento psiquiátrico por dois anos para sua realização. $\mathrm{O}$ desconforto com o sexo anatômico e o desejo de a pessoa modificar a genitália para a do sexo oposto é o principal critério definidor do diagnóstico de transexualismo. A cirurgia de transgenitalização é considerada etapa final do tratamento, e vem sendo admitida pela instância judicial como condição necessária para a alteração da identidade sexual legal. $\mathrm{O}$ artigo discute o conflito moral entre o sujeito transexual e as normas vigentes em relação ao exercício da autonomia individual nas práticas terapêuticas, aplicando as ferramentas da bioética, a partir da análise dos argumentos utilizados pelas instâncias de saúde e judicial sobre o tema, nos artigos, documentos e decisões judiciais nacionais.

Observa-se que houve avanços no acesso aos recursos terapêuticos e legais, mas as limitaçôes e restriçôes ainda impostas ao exercício da autonomia do/a transexual podem ter efeitos negativos para a saúde e os direitos daqueles não considerados pela norma vigente como "verdadeiros transexuais”. Os direitos da pessoa transexual à assistência integral à saúde, inclusive sexual, e ao livre desenvolvimento de sua personalidade são infringidos no momento em que a autonomia do paciente não é adequadamente preservada pelas normas vigentes, convertendo-se os direitos humanos num tipo de dever de a pessoa adequar-se à moralidade sexual dominante.

> Palavras-chave: transexualismo; bioética; medicina; direitos humanos; autonomia individual.

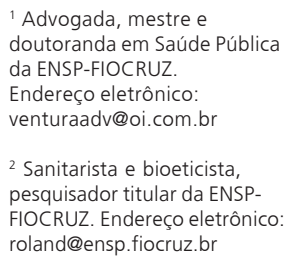

${ }^{1}$ Advogada, mestre e doutoranda em Saúde Pública da ENSP-FIOCRUZ.

Endereço eletrônico:

venturaadv@oi.com.br

2 Sanitarista e bioeticista, pesquisador titular da ENSPFIOCRUZ. Endereço eletrônico: roland@ensp.fiocruz.br 


\section{Introdução}

A transexualidade é amplamente definida como um fenômeno cuja principal característica é o desejo de viver e ser identificado como pessoa do sexo oposto ao seu sexo biológico, e de ter seu corpo modificado para o sexo/gênero com o qual se identifica. Trata-se de um tipo de condição sexual admitida pela Medicina como uma entidade nosológica, denominada transtorno de identidade de gênero (Diagnostic and Statistical Manual of Mental Disorders - DSM-IV) ou sexual (Organização Mundial de Saúde), ou ainda, transexualismo (Conselho Federal de Medicina-CFM), cuja principal característica é o antagonismo entre sexo e gênero, acompanhado de um intenso sofrimento não causado por anomalia sexual ou distúrbio de base orgânica, como as espécies de hermafroditismo.

A possibilidade de se realizar modificaçôes corporais com a finalidade de alterar a identidade sexual reacendeu as discussões sobre os limites da autonomia pessoal em relação às intervenções no próprio corpo e a legitimidade do uso dessas práticas para redefinição do sexo/gênero legal como um direito de liberdade. A problemática moral central refere-se à incorporação dessa possibilidade na prática médica e jurídica, e como seu uso pode afetar, de forma positiva ou negativa, a autonomia do sujeito moral, em suas liberdades individuais, e sua própria integridade física e psíquica, garantidas pelos Direitos Humanos.

A partir da cronologia estabelecida por Castel (2001), o fenômeno transexual, na sua versão contemporânea, revela uma "dialética sutil” que se desenvolveu e resultou na construção de uma doença, com claras disputas e consensos estabelecidos entre as especialidades médicas - entre medicina, ciências sociais, direito e outros saberes - e os movimentos organizados. Ao longo de poucas décadas, a demanda das pessoas transexuais por acesso às modificações corporais e à alteração da sua situação legal vem conseguindo se legitimar a partir (a) dos avanços da biomedicina e da oferta destes recursos na prática médica; (b) da classificação do fenômeno da transexualidade como doença - transexualismo; (c) do estabelecimento de critérios para o diagnóstico; (d) da validação de uma terapia considerada capaz de promover o bem-estar do "doente" afetado; (e) do reconhecimento jurídico do direito da pessoa transexual ao acesso à terapia, constituído por direitos humanos já afirmados, como o direito à saúde, à privacidade, à intimidade, o de não ser discriminado em razão de sua especial condição e ao livre desenvolvimento da personalidade. 
A situação atual é que, apesar do reconhecimento jurídico do direito da pessoa transexual ao acesso às modificaçôes corporais e alteração da sua identidade sexual, a legitimidade dessa prática está condicionada à confirmação de um diagnóstico psiquiátrico e ao cumprimento de um protocolo terapêutico, cujos critérios e condições mínimas são estabelecidos previamente pela instituição médica, e implicam substancial redução da autonomia do sujeito transexual, e dos próprios profissionais de saúde, no processo transexualizador. Em resumo, só é possível o acesso aos recursos disponíveis com a tutela da Medicina e do Direito, e não como uma escolha livre do sujeito transexual, nem como resultado de um acordo entre as partes.

A principal justificativa para as restrições normativas é a intenção de beneficência e de proteção do paciente transexual, considerando as extensas e irreversíveis modificaçóes corporais, e a natureza de sua doença - transtorno psíquico - que pode limitar sua capacidade de decidir sobre as intervençôes adequadas a serem realizadas em seu corpo. Nessa perspectiva, o protocolo diagnóstico e terapêutico responde a uma preocupação ética e jurídica significativa que envolve as práticas de saúde em geral, e se relaciona com o dever do Estado, representado por suas instituições, de proteção das pessoas em face da "pura e simples utilização instrumental" (ARÁN; PEIXOTO JR., 2007, p. 4) e, ao mesmo tempo, de garantir o acesso seguro aos avanços técnicos e científicos de forma igualitária e sem discriminação de qualquer espécie. A hipossuficiência (ao menos técnica) do paciente em relação ao profissional de saúde, por si só, justificaria a produção de normas protetoras da autonomia do paciente no âmbito dos cuidados de sua saúde. A preocupação de proteção aumenta quando se trata de incorporar novas tecnologias, considerando os riscos que podem representar à saúde humana e o fato de que, em sua maioria, são desenvolvidas e introduzidas por um "mercado da saúde" que busca a lucratividade através do aumento do rol de consumidores.

No entanto, o tipo de tutela normativa estabelecida pode não representar um autêntico instrumento de proteção da pessoa, mas um tipo de dispositivo de poder e controle (institucionalizado na Medicina e no Direito), que reduz ou anula a autonomia dos sujeitos, para atender interesses e moralidades dominantes. A resposta dada à demanda transexual foi a criação de um tipo de entidade nosológica - o transexualismo - e de um protocolo diagnóstico e terapêutico que fixa descrições e prescrições sobre como deve ser vivenciada "corretamente" a transexualidade, não se restringindo a estabelecer limites e práticas mais seguras de se realizarem as 
intervençôes. Nesse sentido, o transexualismo pode ser visto como um tipo de dispositivo, no sentido que as instituiçōes médica e jurídica desconsideram as singularidades, e tem como principal preocupação reduzir à condição transexual à heterossexual, admitida como a expressão correta ou normal da sexualidade.

Outro aspecto relevante dessa problemática é que na vigência simultânea dos paradigmas biotecnocientífico e bioético (SCHRAMM, 1996), situados no contexto de uma cultura de direitos humanos (BOBBIO, 1992), as novas possibilidades de intervenções no próprio corpo são admitidas pela maioria das pessoas como algo positivo e indispensável para a ampliação da liberdade pessoal e a melhoria das condições de vida. Os avanços nas práticas médicas vêm oferecendo um leque de escolhas mais amplo às pessoas, não só para prevenir doenças, mas, também, para superar desconfortos em relação ao próprio corpo, justificando-se a percepção social de que o acesso às novidades é positivo e deve ser admitido como um direito fundamental da pessoa. Esta percepção positiva pode aumentar a conflituosidade entre normas que regulam e restringem o acesso a determinadas inovações e sujeitos que reclamam acesso igualitário e sem discriminação de qualquer espécie. Por exemplo, condicionar o acesso às modificações corporais das pessoas transexuais a um diagnóstico psiquiátrico e admitir a prática livre no caso de cirurgias estéticas não constitui uma forma de discriminação no acesso aos recursos de saúde? Como adverte Rodotá (2005), há uma necessidade de se ir além das tradicionais normas de proteção da pessoa face às inovaçôes biotecnocientíficas e avançar na elaboração de normas de promoção do direito das pessoas em face destes avanços que efetivamente protejam aqueles com maior grau de vulnerabilidade ou já vulnerados e, ao mesmo tempo, preservem a autonomia dos sujeitos no âmbito dos cuidados com a sua saúde.

Neste sentido, aumenta a necessidade de uma reflexão capaz de oferecer argumentos sobre os valores e as justificativas a respeito do uso das novidades biotecnocientíficas nas práticas médicas. Essa preocupação se expressa no paradigma bioético, entendido como um "padrão de reflexão e argumentação sobre os valores e suas justificativas a respeito da vigência da competência biotecnocientífica em 'reprogramar' o fenômeno da vida" (SCHRAMM, 1996, p. 115), e no âmbito dos Direitos Humanos, considerados como "instrumentos de libertação individual e social [capazes de] dar uma contribuição essencial para definir a condição humana e, ao mesmo tempo, as modalidades de 
funcionamento dos sistemas jurídicos” (RODOTÀ, 2005, p. 110). Ambos os discursos se revelam capazes de representar uma gramática ou uma linguagem mínima de categorias cogentes e conciliáveis entre si, que pode oferecer ferramentas adequadas para uma análise qualificada dessas novas questões morais, nos diversos contextos sociais e entre grupos e indivíduos diferentes.

É a partir dessa perspectiva - de aplicação simultânea das ferramentas da Bioética e do Direito no campo da saúde - que este estudo busca analisar os limites e possibilidades do exercício da autonomia nas práticas terapêuticas de modificação corporal e alteração da identidade sexual, no âmbito dos sistemas de valores vigentes - moral e jurídico. A discussão abordará especialmente dois aspectos:

(a) a legitimidade de a pessoa transexual realizar, por livre vontade, as modificações corporais que julgar necessária para adequar seu corpo à identidade sexual desejada/vivenciada. Esse aspecto envolve a relação entre médico e paciente, e a relação destes sujeitos com as normas e leis vigentes que limitam os atos de disposição do próprio corpo ${ }^{1}$

(b) a legitimidade de se determinar a identidade sexual através de modificações corporais, admitindo-se que se alterem elementos do estado da pessoa prenome e sexo - a princípio considerados pelo Direito imutáveis e indisponíveis. Esse aspecto envolve também a relação dos sujeitos transexuais com os sistemas legais vigentes, que consideram a existência de apenas dois sexos na definição do estado civil da pessoa, e admitem como sexo legal o sexo biológico, constatado no momento de seu nascimento, a partir da anatomia da genitália.

O material utilizado para esta análise é o resultado de uma pesquisa bibliográfica e documental que reuniu artigos científicos e títulos nacionais da área da Saúde, Bioética e Direito, normas e documentos do setor saúde e do Conselho Federal de Medicina, e as decisões judiciais dos Tribunais Superiores brasileiros, no período de 1988 a julho de 2006 (VENTURA, 2007). O material foi atualizado e reanalisado para a produção do presente artigo.

\section{A transexualidade como fonte de conflitos morais}

De acordo com a literatura pertinente sobre o "fenômeno transexual" e suas metamorfoses (CASTEL, 2001 e 2003), a transexualidade pode ser objeto de vários tipos de conflitos. Alguns relativos às tensões intraindividuais (do indivíduo 
consigo mesmo), outros referentes a conflitos interindividuais (de um indivíduo com outros) e, por fim, conflitos que dizem respeito a indivíduos e populações com as instituições públicas, como o Direito, a Medicina e a Saúde Pública.

Os conflitos intraindividuais podem ser definidos como aqueles resultantes da tensão entre identidade sexual e identidade de gênero, ou entre "identidade corporal e identidade de gênero" (BENTO, 2006), ou, ainda, de "conflito entre sexo físico e sexo psíquico” (HOTTOIS, 2001, p. 848), embora tal tensão possa ser pertinentemente reduzida a um "sentimento intenso e penoso de não pertencer a seu sexo de nascença e de pertencer ao sexo oposto” (CASTEL, 2005). Tal tensão também pode ser indicada pelo prefixo trans-, que aponta a necessidade de usar um "terceiro termo" para definir o fenômeno. O prefixo vem da preposição latina trans, que indica "além de", "para lá de", "depois de", podendo, portanto, referirse a um terceiro termo identitário de difícil colocação lógica e semântica, pois indica ao mesmo tempo uma disjunção e uma conjunção. Ser trans-é não ser nem um nem outro e, ao mesmo tempo, ser um e outro, de acordo com a semântica do verbo "transitar", que implica poder ir de um lado para o outro e vice-versa. Mas a dificuldade em se admitir a possibilidade de transitar de um sexo/gênero para outro é também epistemológica, visto que temos uma alteridade ou uma diferença não assimilável ao interior das tradicionais categorizações dicotômicas como masculino e feminino stricto sensu. Com efeito, a transgressão de tais dicotomias é representada, a princípio, pelo fenômeno/vivência da transexualidade, que não se encaixa no âmbito restrito determinado pelo modelo reducionista do naturalismo, ao qual se tenta confiná-lo como transgressor de uma suposta norma biológica claramente identificável.

Tal dificuldade para pensar o fenômeno da transexualidade como aquilo que de fato é um "terceiro excluído" está inscrita na própria linguagem, pois este terceiro está praticamente excluído tanto (1) da maioria das línguas faladas (o alemão prevê um genérico gênero neutro ou um "ainda não-gênero", que é reservado essencialmente a entes como crianças, além de objetos), como (2) da maioria dos sistemas sociais, que se estruturam pelas duplas macho/fêmea, feminino/masculino, homem/mulher, menino/menina, papai/mamãe, entre outras.

De fato, constata-se que as normas médica e jurídica relacionadas à transexualidade consolidam a naturalização deste sistema binário de sexo/gênero, que não reconhece a existência de outro status sexual, mesmo que a base biológica 
existente seja dúbia, como no caso das pessoas intersexuais. ${ }^{2} \mathrm{Um}$ aspecto importante no tratamento tanto das intersexualidades como da transexualidades é a ideia de sexo/sexualidade relacionada à anatomia da genitália, que se fundamenta na diferença anatômica sexual biológica e estabelece combinações obrigatórias entre seus elementos, tais como: ser mulher é ter uma vagina, ser homem é ter um pênis. Isto confirma que ser "sexuado" é estar submetido a um tipo de regulação, que define que o "verdadeiro sexo" coincide com a naturalização deste sistema normativo, que estabelece as relaçóes e os efeitos desejados entre esses elementos para considerar o que seja uma sexualidade normal ou saudável. Como afirma Bento (2006, p. 47):

quando se diz "transexual" não se está descrevendo uma situação, mas produzindo um efeito sobre os conflitos do sujeito que não encontra no mundo nenhuma categoria classificatória e, a partir daí, buscará comportar-se como "transexual". O saber médico, ao dizer "transexual", está citando uma concepção muito específica do que seja um/a transexual. Esse saber médico apaga a legitimidade da pluralidade, uma vez que põe em funcionamento um conjunto de regras consubstanciado nos protocolos, que visa a encontrar o/a "verdadeiro/a transexual". O ato de nomear o sujeito transexual implica pressuposiçóes e suposições sobre os atos apropriados e não-apropriados que os/as transexuais devem atualizar em suas práticas.

A transexualidade, nesse sentido, pode ser definida como uma experiência de conflito com as normas de gênero que estabelecem, socialmente, a anatomia da genitália para definir homem e mulher e, ainda, que devem ser heterossexuais (BENTO, 2006; VILLELA; ARILHA, 2003). Assim, a definição na norma médica e jurídica passa a considerar um "transexual de verdade" somente aquele que deseje ter uma genitália compatível com o gênero que se expressa e relacionar-se apenas com o gênero oposto, isto é, que seja capaz de reduzir-se a um comportamento de fato "heterossexual" e que a anatomia seja a mais congruente possível com a nova condição. Qualquer desconformidade com estas normas de gênero - como o desejo de viver como mulher, mas com uma genitália masculina, ou relacionar-se sexualmente com outra mulher sendo uma transexual - não autoriza a pessoa transexual a realizar as modificaçôes corporais e a alterar a identidade da maneira desejada.

As teorias e propostas que constituíram o transexualismo tiveram desdobramentos "micro" e "macro", nos quais se desenvolvem conflitos morais diferenciados. No nível micro - relativo ao indivíduo e suas inter-relaçōes com outros indivíduos -, os desdobramentos e conflitos se referem à forma como a 
pessoa se reconhece ou reconhece a outra como transexual. Os de caráter macro "são aqueles que se referem à compreensão que as instituições têm das pessoas transexuais, principalmente a justiça e a medicina, que, diante das demandas para a mudança dos documentos e/ou corpos, fazem avaliações sobre suas feminilidades/ masculinidades" (BENTO, 2006, p. 43) e podem ser relacionados aos conflitos entre os sujeitos e as instituições. A existência desses conflitos que causam sofrimento ao sujeito constitui uma questão moral relevante e aponta para a problemática bioética, que se ocupa da moralidade dos atos significativos de um agente moral sobre o destinatário de tais atos, chamado paciente moral; ou seja, das inter-relações entre esses sujeitos morais, e destes com as instituições - como a Saúde e o Direito -, podendo, a rigor, ocupar-se dos conflitos intraindividuais que se referem à identidade do sujeito, como sugere Paul Ricoeur, ao distinguir dois sentidos de identidade: a identidade-idem - no sentido de idêntico que permanece no tempo - e a identidade-ipse, que "não implica nenhuma asserção concernente a um pretenso núcleo não-mutante da personalidade [e] emprega uma dialética complementar daquela da ipseidade e da mesmidade, isto é, a dialética do si e do diverso de si”, sintetizada pela expressão o si-mesmo como um outro, que "sugere [...] que a ipseidade do si-mesmo implica a alteridade em um grau tão íntimo, que uma não se deixa pensar sem a outra” (RICOEUR, 1991, p. 13-14).

Do ponto de vista bioético, a prática da intervenção médico-cirúrgica sobre o corpo do sujeito transexual - se admitida como um tipo de "terapia" consistente em restabelecer uma espécie de harmonia entre seus estados físico, psíquico e social em conflito, por meio de uma "retificação física” que lhe proporcionará o pertencimento à categoria sexual desejada e seu reconhecimento no plano cível, e for realizada em resposta à sua livre-vontade - tem sua legitimidade moral no princípio de autonomia, aplicável a qualquer indivíduo competente, tanto cognitiva como moralmente. O princípio da autonomia pode, ainda, ser conjugado com os princípios - ao mesmo tempo bioéticos, sanitários e jurídicos - de "qualidade de vida" e de "bem-estar", potencializando a legitimidade das intervenções consentidas pelo sujeito, ou justificadas por suas necessidades terapêuticas, desde que isso não prejudique, de maneira substantiva, terceiros, a não ser, eventualmente, seus preconceitos.

Mas há argumentos contrários, que defendem que o princípio de autonomia não legitimaria essas práticas, se considerarmos a vulnerabilidade, e mesmo a 
incapacidade, da pessoa transexual para decidir livremente sobre as intervenções em seu corpo. O debate e controvérsias, bioéticas e jurídicas, a respeito da autonomia da pessoa transexual no processo transexualizador, e da legitimidade da "terapia" proposta, se assentam na própria compreensão do princípio de autonomia nesses campos, a seguir apresentado.

\section{O princípio ético e jurídico de autonomia pessoal}

Autonomia é um termo que indica a capacidade de alguém determinar-se de acordo com leis próprias (do grego autós, "si mesmo", e nómos, "lei") e tem duas dimensóes: a dimensão prática ou moral, referida à ação, que implica escolha e decisão próprias; a dimensão cognitiva ou capacidade para distinguir a ação apropriada a ser adotada numa situação determinada. Apesar de o conceito possuir poucos consensos acerca dos elementos que o definem, e muitas dificuldades para sua aplicação prática, é considerado um valor moral comum, fruto do humanismo individualista moderno, presente também nas sociedades democráticas e pluralistas contemporâneas (SCHRAMM, 1998). Esta noção da centralidade do indivíduo e do valor correlato da autonomia funda a lógica de regulação pelo Direito - individual, de cidadania e dos direitos humanos em si - fazendo com que as leis reconheçam os espaços de autonomia e autodeterminação dos sujeitos como um dos aspectos fundamentais da sua dignidade e do direito à vida com liberdades.

No debate atual, a autonomia é considerada a principal fonte de valor da ação humana, da prática social e política, e através do seu principal instrumento - o consentimento - serve para conferir legitimidade moral às intervenções na vida das pessoas. A autonomia pessoal passa a ser um conceito-chave na construção dos vínculos entre esfera pública e privada da vida, que estabelece, por exemplo, as possibilidades de interferência de uma esfera na outra, e favorece uma convivência pacífica nas sociedades onde coexistem diversas moralidades num clima de tolerância.

Mas a incorporação da concepção de autonomia nas nossas práticas se torna mais complexa quando se constata que as pessoas são essencialmente seres sociais e que sofrem, portanto, influências. Isto implica reconhecer que não somos capazes de agir exclusivamente por nossas próprias leis, mas, também, em não admitir qualquer influência externa na instituição de nossas leis internas. Nesta dupla negação, a grande dificuldade consiste em identificar quais são os fatores que realmente vulneram e afetam, de forma substancial, a capacidade de 
autodeterminação de um sujeito. Por exemplo, pressupondo que ser "sexuado" é estar submetido a um tipo de regulação que tem efeito performático sobre os sujeitos, o exercício da sexualidade não se esgota na vontade livre, desencarnada e descontextualizada de um determinado sujeito - ou seja, a autonomia e a vontade livre dos sujeitos são elementos indispensáveis e fundamentais, mas não únicos, para a vivência/construção livre de sua autonomia sexual. Neste sentido, é necessário problematizar a concepção moderna de autonomia e relacioná-la com as diversas práticas individuais e sociais, que, no caso da pessoa transexual, inclui as modificaçôes corporais que são viabilizadas pela medicina e identificar os limites e possibilidades de esses sujeitos decidirem, livremente, sobre as transformaçōes em seu corpo e identidade, sem prejuízo de sua proteção e dignidade.

Muitos paradoxos e dificuldades na aplicação do conceito de autonomia na vida prática são identificados, como a impossibilidade de se admitir a concepção da autonomia absoluta do humano e o rigorismo do racionalismo da ética kantiana, que não admite influências subjetivas na reflexão ética (SEGRE, 1999). Porém, todos consideram a possibilidade de as pessoas fazerem escolhas acertadas, mesmo sob certas influências, e a importância da concepção de autonomia para afirmar nossa condição de agentes racionais, com competência cognitiva e moral para decidir, e como condição necessária para responsabilizar o agente moral por suas decisões e ações (SCHRAMM, 1998; KOTTOW, 2000). Assim, a autonomia é incorporada como uma invenção indispensável para a criação de uma ordem básica que "impõe uma legalidade ao mundo [em] que vivemos" (SCHNEEWIND, 2005, p. 528) e torna plausível "sustentar que só os agentes que agem de forma autônoma são responsáveis por suas ações” (BLACKBURN, 1997, p. 32).

A autonomia como conceito central para a análise moral, ou como fundamento da moralidade de uma ação (SCHRAMM, 1998, p. 4), encontra-se incorporada nas diversas teorias bioéticas, com diferentes denominações e extensōes conceituais: princípio da autonomia, princípio do consentimento, princípio do respeito às pessoas - ou respeito à autonomia; e distintas perspectivas, desde as mais individualistas, até as que relacionam a autonomia individual à vivência no grupo social. $\mathrm{O}$ respeito à decisão do paciente, a obrigação moral - pessoal e institucional - de garantir que todos possam estabelecer e manter um projeto de vida próprio, assumindo a responsabilidade por suas decisōes, e "respeitar todas as concepçôes de autonomia das várias comunidades morais como um meio [procedimental] e pacífico de debate" 
(SCHRAMM, 1998, p. 9) são alguns exemplos que buscam dar sentido e aplicabilidade ao princípio da autonomia a partir do paradigma bioético.

$\mathrm{Na}$ prática médica, uma das teorias bioéticas mais difundidas e utilizadas para deliberação de conflitos que surgem na prática biomédica é a teoria dos quatro princípios ou principialismo - respeito à autonomia, beneficência, nãomaleficência e justiça. Seus conceitos estão incorporados nas diversas normas, diretrizes e protocolos de assistência à saúde e de pesquisa em seres humanos. Esta teoria define autonomia como "o governo pessoal do eu que é livre tanto de interferências controladoras por parte de outros como de limitações pessoais que obstam a escolha expressiva da intenção, tais como a compreensão inadequada" (BEAUCHAMP; CHILDRESS, 2002, p. 138). A teoria admite que, para que uma ação seja autônoma, deve-se exigir apenas "um grau substancial de entendimento e de liberdade de alguma coerção, e não um entendimento pleno ou uma completa ausência de influência" (BEAUCHAMP; CHILDRESS, 2002, p. 139), pois caso contrário privaria, de maneira significativa, os pacientes da competência de tomarem decisões sobre si mesmos. Nesse sentido, incorpora o "princípio de respeito à autonomia", exigindo apenas que as açôes sejam substancialmente autônomas, e não dependentes de uma condição ideal de exercício da autonomia; possibilitando, por exemplo, que pessoas consideradas incapazes pela lei - como as crianças - sejam, em determinadas circunstâncias, consideradas capazes de fazer escolhas parcialmente autônomas.

Outro aspecto importante desta teoria é a ênfase dada à dimensão individual do agente autônomo e à dimensão relacional dos agentes morais, considerada indispensável para o exercício da autonomia. Na relação médico-paciente, a aplicação do princípio do respeito à autonomia (e não simplesmente o princípio da autonomia) implica que a equipe de saúde reconheça a priori (antes de qualquer juízo ou avaliação sobre a condição autônoma ou não do paciente) o direito de a pessoa expressar suas opiniōes, fazer suas escolhas e agir, com base em valores e crenças próprias, garantindo-lhe, efetivamente, a possibilidade de seu exercício. Isso se traduz em obrigações de não-intervenção nas decisões do outro - obrigações negativas - e as de sustentar a capacidade do agente para escolher autonomamente e proporcionar as condiçōes necessárias para isso obrigações positivas. O consentimento informado, ou - como admitido nas normas brasileiras - livre e esclarecido, é o principal instrumento para garantir 
o exercício da autonomia, entendido como expressão concreta da vontade do agente moral nas intervençôes médicas e de pesquisa.

Mesmo considerando que o princípio do respeito à autonomia pode melhor garantir a autonomia dos agentes morais, a teoria principialista considera insuficiente a adoção de um único princípio moral como norteador da análise dos problemas éticos no âmbito biomédico. Assim, incorpora três outros princípios, que serão hierarquizados e aplicados de acordo com o caso concreto (ou contingências), a partir de critérios estabelecidos a priori: os princípios de beneficência, de não-maleficência e de justiça. O método utilizado para deliberação é o da ponderação dos princípios, que admite a priorização de um dos princípios, de acordo com as características pertinentes de cada situação. As possibilidades restritivas da autonomia individual no âmbito da saúde pública - por exemplo, para conter o avanço de determinada doença na coletividade - e as intervenções médicas emergenciais não consentidas pelo paciente - visando a preservar sua vida - seriam alguns exemplos de restrições em princípio moralmente justificáveis.

No âmbito jurídico, o conceito de autonomia não se afasta substancialmente do admitido nas teorias morais. Autonomia é entendida como liberdade de ação e está associada à garantia de prerrogativas legais para decidir livremente sobre aspectos da sua vida pessoal, que - por exemplo, na relação médico-paciente - objetiva limitar o poder médico em suas intervençôes no paciente. Um ponto de consenso na discussão jurídica atual - que converge com a concepção da teoria dos quatro princípios - é que a autonomia do indivíduo, em relação a sua própria vida e/ou atos de disposição de partes de seu corpo, não é ilimitada, e a liberdade e autonomia do indivíduo em relação a sua própria vida deve ser limitada/substituída pela noção de proteção e garantia à dignidade da pessoa humana (MORAES, 2003). O método mais comum utilizado na deliberação jurídica quando ocorre conflito de princípios, direitos e interesses, é o da ponderação destes no caso concreto, definindo-se como solução adequada o resultado que permita garantir que o bem sacrificado encerre menor valor que o bem-interesse atendido. No caso das práticas de modificações corporais e alteração da identidade, o bem sacrificado considerado é o corpo, que sofrerá extensas e irreversíveis transformaçōes, com riscos potenciais para saúde física do indivíduo; e o bem-interesse a ser atendido é o bem-estar que a "retificação corporal" proporcionará para o pertencimento desse indivíduo à categoria sexual desejada e seu reconhecimento no plano cível. 
Há duas grandes linhas argumentativas no Direito sobre os limites e as possibilidades da autonomia da pessoa em relação aos atos de disposição do próprio corpo para atender a um interesse pessoal. Uma que sustenta a absoluta impossibilidade de livre disposição do corpo humano por ato de vontade do sujeito, fundamentada no princípio da sacralidade da vida ou no direito natural (DALLARI, 2005; LEIVAS, 2007). Esta corrente considera que a vida e o corpo são bens indisponíveis, concedidos por Deus ou pela natureza, e, se não foram outorgados/ adquiridos por nenhuma lei socialmente estabelecida, não podem ser disponibilizados nem mesmo por seu detentor. Assim, admite uma única forma digna (ou permitida) de disposição, que é a intervenção no corpo para manutenção e recuperação da saúde física do seu detentor. A conclusão é a ausência completa de autonomia pessoal e a prevalência dos princípios da beneficência e da nãomaleficência na solução dos conflitos.

Os segmentos mais liberais buscam ponderar a aplicação do direito à vida, entendida no seu aspecto psicofísico e moral, e o direito à saúde - entendido como um completo bem-estar - com o princípio da qualidade de vida e, a partir desta ponderação, estabelecer os limites e as possibilidades para a pessoa decidir sobre o que considera um bem para si. Reconhecem, assim, um grau maior de autonomia pessoal, e o consentimento livre e informado do paciente ganha, neste sentido, maior relevância. Esta concepção foi largamente incorporada nos sistemas jurídicos vigentes, que em sua maioria preservam a vontade individual como condição necessária, embora não suficiente, para se dispor livremente do próprio corpo e, portanto, restringir ou limitar o acesso a determinadas práticas e produtos.

Para compreender os limites e possibilidades do exercício da autonomia da pessoa transexual no processo transexualizador, é importante delinear o contexto normativo que abriga e organiza a discussão sobre a legitimidade dessas práticas.

\section{O contexto normativo brasileiro e a legitimidade das modificaçõos corporais para alteração da identidade sexual}

Apesar de a prática de modificação corporal ser uma expressão comum da identidade, presente em diversas culturas, "não são claros os limites entre a livre disposição do corpo como projeção do desenvolvimento da personalidade e identidade e a sua mutilação como ato patológico" (KONDER, 2003, p. 65) ou como violação de direitos humanos (COOK et al., 2004). O fato é que na maioria 
dos países as leis limitam as intervenções médicas que importem em diminuição permanente de funçôes e da integridade física da pessoa, justificada pelo dever do Estado de proteger a pessoa humana. Igualmente, as leis estabelecem a imutabilidade de alguns elementos do estado civil da pessoa (o sexo é um deles), justificada pelo dever do Estado em garantir a segurança nas relações pessoais e institucionais, basicamente de natureza patrimonial - contratual e de herança - e de preservação da instituição familiar, relacionada à filiação e ao matrimônio (PERES, 2001; FRIGNET, 2002).

\section{Da legitimidade do processo transexualizador}

A discussão ética e jurídica brasileira sobre o acesso das pessoas transexuais às modificaçôes corporais e alteração da identidade sexual teve início na década de 70 e, até os anos 90, concentrou-se nos aspectos penais e deontológicos do ato médico e no argumento de que a retificação do corpo da pessoa transexual não era uma terapia válida para o tratamento. O Conselho Federal de Medicina defendia, até o ano de 1997, a ilegalidade das intervençôes médicas transexualizadoras, com base no Código Penal Brasileiro, ainda vigente, especialmente os crimes de lesão corporal (aplicado ao médico) e falsidade ideológica (aplicado ao transexual), combinado com o dispositivo do Código de Ética Médica, que veda a realização de ato médico proibido por lei.

Com a aprovação, em 1988, da Constituição Federal do Brasil, um rol de princípios éticos de direitos humanos é introduzido no sistema legal brasileiro, alterando o conteúdo e a metodologia de aplicação das leis nacionais. Os princípios ético-jurídicos passam a ser elementos essenciais na interpretação e aplicação das leis, ampliando as possibilidades de atualização e adequação dos preceitos legais à realidade social. $\mathrm{O}$ novo ordenamento jurídico dá especial enfoque às liberdades e aos direitos fundamentais das pessoas, favorecendo a mudança de perspectiva no debate jurídico sobre o acesso dos/as transexuais aos recursos médicos e jurídicos para a alteração da identidade. O direito à saúde, como direito fundamental conjugado com as liberdades e outros direitos fundamentais garantidos - como o direito à intimidade, à privacidade e à inviolabilidade da integridade física e moral - permitem interpretações favoráveis à demanda dos/as transexuais.

A primeira decisão da qual se tenha notícia é a do Superior Tribunal Federal (STF), sobre a condenação criminal e ético-profissional - por crime de lesão corporal 
- de um cirurgião que realizou a cirurgia de transgenitalização. O STF reconheceu a licitude do ato médico, fundamentado na necessidade terapêutica e na competência técnica dos profissionais (CHAVES, 1981). Porém, a decisão da Suprema Corte não alterou o entendimento do Conselho Federal de Medicina (CFM), que até o ano de 1997 manteve o entendimento de que a prática das modificações corporais para alteração da identidade sexual não era terapêutica, mas, sim, mutiladora (CFM, 1991).

Com a aprovação da Resolução CFM n. ${ }^{\circ} 1.482$, de 1997, o CFM reconheceu a natureza terapêutica dessa prática médica, autorizando a cirurgia de transgenitalização e os procedimentos complementares sobre gônadas e caracteres sexuais secundários, nos casos de transexualismo, como tratamento experimental, o que restringia sua realização no âmbito da pesquisa médica, conforme Resolução do Conselho Nacional de Saúde - CNS no 196, de 10/10/1996. No ano 2002, a Resolução CFM no 1.652 alterou a anterior, permitindo que a cirurgia do tipo neocolpovulvoplastia fosse realizada no âmbito da assistência à saúde, em qualquer instituição pública ou privada de saúde. Manteve-se, contudo, o caráter experimental da cirurgia de neofaloplastia, por sua maior complexidade técnica em relação à construção de um pênis e sua funcionalidade sexual. Os demais critérios e condiçôes para o acesso ao tratamento foram mantidos.

Só recentemente o acesso ao processo transexualizador foi incorporado na rede assistencial do Sistema Único de Saúde (SUS), através da Portaria do Ministro da Saúde no 1.707 , de 18 de agosto de 2008, que incorpora os critérios e condições para o acesso estabelecidos na Resolução CFM n. ${ }^{\circ}$ 1.652/2002 e dá as seguintes diretrizes para o atendimento e organização dos serviços: integralidade e humanização da assistência; desenvolvimento de estudos sobre a eficácia, efetividade, custo e benefício e qualidade do processo transexualizador para a pessoa transexual; capacitação, manutenção e educação permanente das equipes. A incorporação da integralidade da assistência - entendida como a não-restrição e centralização da "meta terapêutica no procedimento cirúrgico de transgenitalização e demais intervenções somáticas aparentes ou inaparentes" - e do desenvolvimento de estudos sobre o processo terapêutico são aspectos normativos importantes e favoráveis à superação de algumas dificuldades e preocupações apontadas nos estudos, relacionadas à centralidade do procedimento cirúrgico no protocolo diagnóstico e terapêutico, e ao acompanhamento pós-cirúrgico dos pacientes, não previsto na norma do CFM. A 
inclusão do processo transexualizador no SUS tem um longo processo de negociação e mobilização do segmento transexual e de profissionais de saúde, inclusive por meio de ação judicial, ${ }^{3}$ e espera-se que sua incorporação no sistema de saúde amplie o acesso e a qualidade da assistência à saúde deste segmento.

Os critérios normativos atuais de seleção dos pacientes para o processo transexualizador são: a) avaliação de equipe multidisciplinar constituída por médico psiquiatra, cirurgião, endocrinologista, psicólogo e assistente social; b) a conclusão do diagnóstico médico de transexualismo após no mínimo dois anos de acompanhamento conjunto; c) que o paciente seja maior de 21 anos; e d) que possua características físicas apropriadas para a cirurgia (CFM, 2002, art. 4). O protocolo terapêutico é dividido em uma fase de diagnóstico, seguida das intervenções da equipe de saúde propriamente ditas, que abrange psicoterapia, terapia hormonal, cirurgias e acompanhamento pós-cirúrgico. Os critérios para o diagnóstico são: a) desconforto com o sexo anatômico natural; b) desejo expresso de eliminar os genitais, perder as características primárias e secundárias do próprio sexo e ganhar as do sexo oposto; c) permanência desses distúrbios de forma contínua e consistente por, no mínimo, dois anos; d) ausência de outros transtornos mentais ou anomalias sexuais de base orgânica (CFM, 2002). A equipe de saúde está autorizada a realizar todas as intervenções necessárias para o alcance de um melhor resultado do tratamento e padrão estético compatível com o sexo desejado pela pessoa, como, por exemplo, as cirurgias de fonocirurgia, mamoplastia, masterectomia, histerectomia, dentre outras (ATHAYDE, 2001; SAADEH, 2004), desde que atendidos os critérios mínimos estabelecidos na norma vigente. Em linhas gerais, o consenso clínico atual para o tratamento do transexualismo mantém o tripé psicoterapia/tratamento hormonal/ cirurgia de "redesignação sexual” (SAADEH, 2004).

Além dessas normas específicas, o sistema legal brasileiro conta com alguns dispositivos aplicáveis à questão e que vêm servindo para fundamentar e estabelecer alguns limites às intervençōes. Em nível constitucional, os principais dispositivos são: o direito de não ser submetido a tratamento degradante ou desumano; o direito à inviolabilidade da vida privada, da intimidade, da honra e da imagem da pessoa; $\mathrm{o}$ livre desenvolvimento da personalidade e a autonomia; a não-discriminação, a assistência integral à saúde, entendidas como ingredientes do estado de completo bem-estar (BRASIL, 1988: art. 5º, caput, art. 196). A Constituição Federal permite os atos de disposição do próprio corpo, de forma gratuita e para fins de tratamento 
ou pesquisa, nos limites legais estabelecidos (BRASIL, 1988, art. 199, $\$ 4^{\circ}$ ). O Código Civil Brasileiro trata as questôes de intervenções médicas nos art. 13 e 15, vedando qualquer intervenção que importe na diminuição permanente da integridade física sem finalidade terapêutica, com ou sem consentimento do paciente (art. 13.), ressalvando o direito do paciente de recusar tratamento médico ou intervenção cirúrgica que possa trazer risco de morte (art. 15). Os dispositivos do Código Civil vêm sendo interpretados e aplicados em conformidade com os artigos constitucionais suprarreferidos, o que vem permitindo uma paulatina ampliação da autonomia dos pacientes nos cuidados de sua saúde, afirmando-se o direito de o paciente decidir livremente sobre a execução de quaisquer práticas diagnósticas ou terapêuticas, salvo em caso de iminente perigo de morte.

As normas vigentes expressam a priorização do princípio da beneficência nas práticas médicas e nas intervenções no corpo humano. Nesse sentido, admitem que "a beneficência fornece a meta e o fundamento primordiais da medicina e da assistência à saúde, enquanto o respeito à autonomia (e a não-maleficência e a justiça) é que estabelece os limites morais das açôes dos profissionais ao buscar essa meta" (BEAUCHAMP; CHILDRESS, 2002, p. 297). O respeito à autonomia do paciente é incorporado nesse modelo na medida em que os interesses dos pacientes convergem com os interesses e fins estabelecidos pela Medicina e o Direito nesse âmbito, justificados pelo dever de proteção à integridade psicofísica e moral das pessoas.

Ao atribuir-se caráter terapêutico às modificações corporais com o propósito de alterar a identidade sexual, permitiu-se a constituição de um permissivo ético e legal para o acesso aos recursos médicos. Porém, aspectos que merecem maior aprofundamento são o efeito estigmatizante e discriminatório do diagnóstico psiquiátrico de uma condição sexual, considerado necessário para o acesso aos recursos médicos disponíveis, e se as restrições à autonomia do paciente, com o objetivo de proteger a pessoa transexual e limitar as intervenções médicas, são efetivas e eficazes.

O que se constata é que o exercício da autonomia do paciente transexual no processo transexualizador é mais limitado do que o usualmente admitido para outros processos terapêuticos, o que traz desafios e dificuldades para os profissionais de saúde, e efeitos negativos para a saúde das pessoas que utilizam a prática de modificações corporais, mas que não são diagnosticadas como "transexuais verdadeiros", já que são excluídos, para esse fim, da assistência do sistema oficial de saúde, buscando recurso no mercado clandestino. 


\section{A legitimidade da alteração da identidade sexual}

Além das dificuldades de acesso aos recursos médicos para as modificações corporais, temos ainda aquelas relacionadas às questôes do estado civil da pessoa submetida ao processo transexualizador. Como afirma Frignet (2000, p. 93), "esse imperativo [da alteração legal do nome e do sexo] é tão poderoso que, para certos médicos, assistentes médico-sociais e também, curiosamente, para alguns juristas ou magistrados, a mudança de estado civil torna-se parte integrante da terapêutica”. Os estudos brasileiros confirmam que um dos maiores obstáculos para inclusão social e afetiva da pessoa transexual se refere às questóes jurídicas relacionadas à mudança de nome e sexo no Registro Civil e consolidam a concepção - inclusive na jurisprudência nacional - de que a alteração da identidade do sujeito transexual é parte integrante e fundamental do tratamento (ATHAYDE, 2001; SAADEH, 2004; SOUZA, 2004; CARDOSO, 2005).

Não há no Brasil lei específica que regule o direito de a pessoa transexual alterar o prenome e o sexo no registro civil e seus efeitos jurídicos. A possibilidade de realizar essas alterações vem sendo viabilizada por meio de requerimento judicial individual, e a decisão judicial é estabelecida a partir da interpretação da lei geral civil brasileira, aplicada às circunstâncias concretas e individuais de cada requerente. A lei civil brasileira assegura a toda pessoa o direito a um nome (prenome e sobrenome), protegendo-o contra qualquer exposição que possa causar "desprezo público, ainda que não haja intenção difamatória” (BRASIL, 2002a: art. 16 e 17); reconhece o direito de adotar-se um pseudônimo para fins lícitos (BRASIL, 2002a: art. 19), por exemplo, o uso de um nome feminino ou masculino por transexuais, para evitar constrangimentos públicos, e ainda garante que a vida privada seja inviolável, cabendo ao juiz - se requerido - as providências necessárias para impedir ou fazer cessar qualquer ato atentatório a este direito (BRASIL, 2002a: art. 21). O sistema legal brasileiro não veda expressamente a possibilidade de alteração da identidade sexual, e as leis gerais vêm permitindo uma interpretação adequada à demanda da pessoa transexual, na medida em que as situações legais - que permitem alterações no estado civil - configuram situações vivenciadas pelas pessoas transexuais no seu dia-a-dia, e fundamentam os pedidos judiciais e as decisões favoráveis à alteração do prenome e sexo no registro civil.

Mas a situação jurídica das pessoas transexuais que se submeteram às modificações corporais e desejam alterar a identidade sexual legal ainda é de 
instabilidade. Apesar do avanço considerável nas últimas décadas, ainda são identificadas decisões desfavoráveis às alteraçôes, especialmente a do sexo legal. $\mathrm{O}$ conteúdo das decisões também é diversificado. Algumas, por exemplo, estabelecem que fique inscrita a condição de transexual no registro, o que não atende integralmente à demanda de reconhecimento no plano cível da identidade de gênero adotada. É importante ressaltar que a alteração do sexo legal não é trivial para o sistema legal, que reconhece alguns direitos e obrigaçóes diferenciadas para homens e mulheres, como a prestação de serviço militar obrigatório, tempo de aposentadoria, e outras relativas aos direitos de família, como maternidade e paternidade, filiação, casamento, que podem atingir direitos de terceiros. Daí a importância de se prever a extensão dos efeitos da alteração da identidade sexual. Há, portanto, uma demanda do segmento transexual, de juristas e profissionais de saúde, e do próprio Poder Executivo, de aprovação de uma lei federal que estabeleça, previamente, os critérios para a alteração do prenome e do sexo legal e seus efeitos. A vantagem de uma lei federal é estabelecer critérios universais para o acesso à alteração; a desvantagem é que uma nova lei pode estabelecer critérios mais restritivos do que os atualmente adotados.

A primeira decisão brasileira identificada sobre o tema foi a do Supremo Tribunal Federal no ano de 1981. A decisão foi desfavorável à alteração do sexo, concluindo que o estado da pessoa "consiste nas relaçôes que a natureza e a lei civil estabelecem, independentemente da vontade das partes, e entre um indivíduo e aqueles de quem recebe o nascimento. $\mathrm{O}$ estado, pois, constitui uma realidade objetiva, de que cada um é titular, e que usufrui com exclusividade. Seus atributos são pessoais e sua essência é irrenunciável" (STF, AR, 1981, no 82.517, p. 3). Somente no ano de 1991 foi identificada uma decisão favorável do Tribunal de Justiça do Rio Grande do Sul, que admitiu que "[se tratando] de transexualismo e, no caso, a cirurgia efetivada como solução terapêutica dos conflitos psíquicos decorrentes de naturezas antagônicas no caráter e na sexualidade, comporta [a] legitimação perante a sociedade e a organização jurídica [a alteração do pré-nome e sexo]" (Apelação Cível no 591019831 TJRGS, 1991).

A tese do STF, fundamentada no determinismo biológico e na impossibilidade jurídica de se admitir um novo sexo, foi majoritária até o ano 2000, quando começa a se firmar a tese favorável à alteração do prenome e do sexo, respaldada na finalidade terapêutica da alteração da identidade civil, e fundamentada no dever constitucional 
do Estado de promover e proteger a saúde e os direitos de cidadania da pessoa. $\mathrm{Na}$ pesquisa realizada nos Tribunais Superiores Brasileiros, no período de janeiro de 2000 a outubro de 2006, registraram-se dez decisões desfavoráveis, e um total de 18 favoráveis. As decisões judiciais desfavoráveis seguem a tese do STF; as favoráveis destacam: a finalidade terapêutica das modificações corporais e a irreversibilidade da condição feminina - e/ou masculina - vivenciada pelo/a paciente; a aceitação social do requerente como pessoa do sexo/gênero que requer a realização do tratamento médico; a realização de todas as etapas do tratamento médico; os constrangimentos pessoais e sociais, e as dificuldades de acesso a bens, serviços e direitos em razão do antagonismo entre sua identidade social e legal.

Os respaldos e fundamentos das decisões judiciais favoráveis indicam que o Judiciário ainda não admite pura e simplesmente o direito à identidade de gênero como uma escolha da pessoa, mas, sim, como "um drama pessoal que encontra definição e respaldo na ciência médica e psicológica que o impeliu para uma final realização terapêutica que encontra o seu clímax na sentença retificadora de sua condição sexual e do seu nome" (Apelação Cível n. ${ }^{85}$ 199-6, 2003). A concepção de que a intervenção judicial constitui etapa final do processo terapêutico proposto pela medicina é muito forte, e as decisóes judiciais buscam relacionar a linguagem médica do protocolo diagnóstico e terapêutico e a linguagem jurídica, para admitir a possibilidade de alteração. Por exemplo, o principal critério definidor para o reconhecimento legal da nova identidade sexual é se o/a paciente já realizou a cirurgia de adequação da genitália, não sendo reconhecida a procedência dos pedidos de alteração da identidade sexual daqueles que se identificam com o gênero oposto ao do seu sexo legal, mas não modificaram a genitália, apesar das alegações de constrangimentos pessoais e sociais para o exercício de seus direitos de cidadania em razão do antagonismo entre sua identidade sexual social e a legal. As decisões revelam que, de fato, o Judiciário não garante plenamente o direito ao livre desenvolvimento da personalidade, a inclusão social e os direitos de cidadania para todos, mas tão somente o direito daqueles considerados pela Medicina como "verdadeiros transexuais" e que se submeterem à cirurgia da genitália. De fato, o Judiciário vem garantindo um tipo de direito à adequação social, desde que cumpridas as normas médicas estabelecidas para a "correção do desvio".

A força do argumento terapêutico para fundamentar o direito à alteração da identidade sexual legal está expressa na única decisão judicial identificada, que 
ressaltou admitir, tão somente - e em caráter excepcional - a alteração da identidade sexual sem que o requerente tivesse se submetido à cirurgia de transgenitalização. $\mathrm{O}$ caso envolvia um pedido de pessoa nascida com sexo feminino para o masculino, e o fundamento da decisão foi que a cirurgia para construção de um pênis implicava risco, conforme documentos médicos comprobatórios, à integridade física e agravamento do estado de saúde do requerente, e que as modificaçôes já realizadas eram irreversíveis, e o mesmo já vivia como pessoa do sexo masculino (Apelação Cível n. $\left.{ }^{\circ} 70011691185,2005\right)$.

Conclui-se que ambas as linhas argumentativas - favoráveis e desfavoráveis admitem como pressuposto a natureza patológica do transexualismo e a necessidade de modificaçōes corporais para a alteração da identidade sexual/gênero, divergindo apenas no sentido da validade e eficácia da terapia, e na possibilidade de o Direito reconhecer um sexo que não seja o determinado exclusivamente por fatores biológicos. O fato é que tanto a Medicina quanto o Direito só admitem, até o momento, um sexo não-biológico como uma expressão doentia da sexualidade, fazendo-se necessária a tutela da Medicina, especialmente da psiquiatria, e a mediação do Direito para legitimar as intervenções corporais. Não há, portanto, a admissão pura e simples da identidade sexual/gênero como construção social ou da subjetividade pessoal, ou ainda, como uma prerrogativa pessoal do sujeito. A formulação favoreceu que o Direito admitisse a possibilidade de se reconhecer juridicamente a alteração da identidade sexual/gênero por iniciativa da pessoa, mesmo que tutelada pela Medicina. Assim, afastou-se a tese do determinismo biológico, substituída pela tese do determinismo anatômico, que obriga que a pessoa transexual, para alterar sua identidade sexual, se submeta a intervenção médica nem sempre desejada ou necessária para a vivência livre de sua sexualidade, como a cirurgia de genitália.

\section{Dificuldades e desafios na aplicação das normas vigentes}

Se as normas médicas possibilitaram efetivamente o acesso dos transexuais às transformações corporais desejadas num sistema oficial de saúde, não se pode deixar de questionar os efeitos negativos desta regulamentação; especialmente, a relação entre autonomia e beneficência e a ponderação desses princípios no âmbito das normas diagnósticas e terapêuticas. O ponto nodal é que as normas vigentes condicionam o acesso às modificaçôes corporais para a alteração da identidade 
sexual à confirmação do diagnóstico psiquiátrico que afirme ser o paciente um "verdadeiro transexual", e cujo principal critério definidor seja o desejo de a pessoa modificar a genitália e, consequentemente, considerar-se a cirurgia como etapa obrigatória e final do tratamento.

Vários estudos identificados comprovam que o fenômeno transexual não possui características específicas e únicas. Saadeh (2004) admite que a imposição normativa de características únicas e específicas para o transexualismo traz muitas dificuldades para a elucidação do diagnóstico do transexualismo e nas relações médico-paciente. De fato, o diagnóstico tornou-se um tipo de habeas corpus médico-psiquiátrico, que estabelecerá o direito ao acesso às transformações corporais somente aos "verdadeiros transexuais" e excluem outras "transexualidades" ou condições que utilizam a prática das modificações corporais, como no caso dos travestis. Em particular, Arán (2006, p. 10) considera que "estabelecer a priori que transexuais padecem de uma patologia ou são necessariamente, por uma questão de estrutura, psicóticos, e ceder de imediato ao apelo do imperativo tecnológico e científico que pretende capturar e modelar os corpos" não constitui uma boa prática psicanalítica, pois traz efeitos potencialmente danosos ao paciente. Por sua vez, Zambrano (2003, p. 5) constata, em sua investigação antropológica, que

apesar de ser um dos critérios diagnósticos para o transexualismo, a cirurgia não é desejada por vários informantes entrevistados que alegam ser transexuais e não querer a cirurgia devido ao risco e consequências, mas que ficam, por isto, impossibilitados de trocar os documentos, já que o Direito não pode declarar como homem alguém que não tem pênis ou mulher alguém que o tem.

Para além das dificuldades na assistência à saúde, Chiland (1999) destaca as dificuldades e inconsistências argumentativas ao negar-se aos transexuais a alteração de seu nome e do sexo. Lembra a autora que a imutabilidade do estado civil da pessoa está relacionada tão somente ao sexo - que é um dado inscrito no corpo - e que qualquer mudança implica alterar este corpo, pois a lei possibilita a mudança do nome quando do matrimônio, do divórcio, e em relação às alterações de filiação (adoção e reconhecimento de paternidade/maternidade). Assim, em princípio não é possível alterá-lo, em razão do determinismo biológico, que só se pode compreender facilmente a partir de uma perspectiva religiosa de que o ser humano não tem o poder de alterar a própria natureza - criada por Deus -, o que é incompatível com a atual concepção de que a moralidade das ações e das leis deve 
estar fundamentada no próprio sujeito e adstrita a um contrato social, e não mais na natureza ou na vontade divina. Como afirma Rodotà, o estado das pessoas que se inscreve nos registros civis é uma descrição do papel social vinculado a um dado biológico "presumidamente imutável" (RODOTÀ apud PERES, 2001, p. 172). Neste sentido, devemos utilizar respaldos científicos como os avanços genéticos que identificam, por exemplo, que um indivíduo pode possuir características dos dois sexos, em prol da ampliação das liberdades, revendo alguns critérios estabelecidos pelo Direito; dentre eles, os critérios de identificação civil assentados no determinismo biológico. Os conceitos-chave para tais mudanças - segundo Rodotà (PERES, 2001) - são o de autonomia da vontade da pessoa e da concepção da vida privada. Em relação ao conceito de vida privada - que se relaciona com o de autonomia -, o autor sugere que não deva ficar estritamente vinculado às noções de segredo e privacidade, mas que deva englobar o modo de vida escolhido voluntariamente pela pessoa, o qual merece igual proteção contra o controle público e o estigma social.

\section{Considerações finais}

No modelo normativo vigente no Brasil, a autonomia da pessoa transexual tem valor instrumental e é funcional à necessidade de se realizarem as intervenções médicas para adequação psíquica e social dos portadores da anomalia sexual definida na norma. Assim, a autonomia pessoal se restringe à faculdade de a pessoa buscar tratamento e aceitar realizá-lo, não de um exercício da livre vontade da pessoa e de escolha do que é mais benéfico para si. O "bem/bom" ou o "certo/errado" para a pessoa transexual são determinados pela norma médica institucional e respaldada pela norma legal. Constata-se que é a perspectiva da beneficência que prepondera, relacionando benefícios e/ou não-malefícios que podem ser obtidos pelo paciente através do tratamento, a partir da avaliação médica, inclusive no âmbito judicial quando decide sobre a alteração da identidade sexual. É justamente nos conflitos sobre o que constitui benefício ou não-malefício para o paciente em determinadas circunstâncias, e a divergência entre o que o saber médico e jurídico considera um "bem", e o que o paciente considera "bom" para si, que se revelam as maiores dificuldades e obstáculos à assistência integral à saúde, proteção e garantia de direitos fundamentais do segmento transexual, inclusive de sua integridade física.

O tratamento dado ao consentimento da pessoa transexual no âmbito das práticas terapêutica é o de um ato de iniciativa que deve externar apenas o desejo 
de tratamento, já que a escolha das intervenções necessárias para seu bem-estar é limitada ao protocolo terapêutico. Algumas afirmaçôes bastante comuns nos estudos analisados são:

adequar o sexo não é uma questão de querer, mas de estar habilitado, [nesse sentido] o puro e simples consentimento do paciente não será suficiente para fazer cair por terra o principio da integridade física. Para que tal fato ocorra, este deverá estar atrelado à necessidade terapêutica comprovada (VIEIRA, 2000, p. 75).

Outra afirmação comum é que:

na hipótese de transexualismo não se está falando de um ato de vontade do cidadão, mas de uma moléstia que nenhum cidadão escolhe ter. Assim, o transexualismo não decorre diretamente da invocação do direito de dispor de seu próprio corpo, como uma variante do direito à liberdade sexual. O transexualismo, no plano jurídico, decorre do direito ao livre desenvolvimento da personalidade [e dignidade da pessoa humana] (BORDAS et al., 2000, p. 173).

Neste sentido, o consentimento da/o transexual para as intervenções é considerado necessário, mas não suficiente, "uma vez que este é mais um campo em que o ordenamento [jurídico] não prioriza a esfera de livre autonomia da vontade" (KONDER, 2003, p. 70-71).

A restrição à autonomia dos sujeitos nesse âmbito tem ainda, como consequência, a exclusão, no sistema oficial de saúde, do/a paciente que não preencha os critérios do diagnóstico para o acesso às modificações corporais. Isto implica que as pessoas excluídas busquem as modificações corporais (implante e aplicação de silicone, ingestão de hormônio e outros) no mercado clandestino ou as realizem elas mesmas, o que implica riscos e mesmo danos irreversíveis para sua saúde e integridade física. A restrição normativa à autonomia resulta também num problema de saúde pública, na medida em que não favorece a adequada proteção e promoção da saúde de todas as pessoas que utilizam as práticas de modificações corporais, afastando-as do sistema de saúde oficial. Neste sentido, entende-se que o respeito ao princípio da autonomia é violado, sem justificativa ética e legal razoável e consistente, no momento em que condiciona o acesso às modificaçóes corporais para alteração da identidade sexual à confirmação do diagnóstico psiquiátrico de transexualismo, que tem como principal critério definidor o desejo de a pessoa modificar a genitália para a do sexo oposto, centrando a meta terapêutica na cirurgia da genitália. 
Outras implicações e repercussões, em relação à adoção da tese do determinismo anatômico certamente existem, devem ser identificadas, aprofundadas e analisadas no sentido de proporcionar a pessoa transexual, assistência integral à sua saúde e aos direitos de cidadania.

\section{Referências}

APELAÇÃO CÍVEL n. ${ }^{\circ} 70011691185$. 8a Câmara Cível. Tribunal de Justiça do Rio Grande do Sul. 2005; 15 set. Disponível em: www.tj.rs.gov.br Acesso em: 08 nov. 2006.

APELAÇÃO CÍVEL no . 591019831. 4a Câmara Cível. Tribunal de Justiça do Rio Grande do Sul 1991; 05 jun. Disponível em: www.tj.rs.gov.br Aesso em: 08 nov. 2006.

APELAÇĀO CÍVEL no ${ }^{\circ}$ 85199-6. $5^{a}$ Câmara Cível. Voto do Relator. Tribunal de Justiça do Estado de Pernambuco; 26 fev. Disponível em: www.tjpe.gov.br Acesso em: 08 nov. 2006.

ARAN, M. A transexualidade e a gramática normativa do sistema sexo-gênero. Agora. Rio Janeiro, v. 9, n. 1, p. 49-63, jun 2006.

ARAN, M.; PEIXOTO JUNIOR, C. A. Vulnerabilidade e vida nua: bioética e biopolítica na atualidade. Rev. Saúde Pública, v. 41, n. 5, p. 849-857, 2007.

ATHAYDE, A. V. L. Transexualismo masculino. Arq Bras Endocrinol Metabol., v. 45, n. 4, p. 407-414, 2001.

BEAUCHAMP, T. L.; CHILDRESS, J. F. Princípios de ética biomédica. São Paulo: Loyola, 2002.

BENTO, B. A reinvenção do corpo: sexualidade e gênero na experiência transexual. Rio de Janeiro: Garamond, 2006.

BLACKBURN, S. (org.). Dicionário Oxford de Filosofia. Rio de Janeiro: Jorge Zahar, 1997.

BOBBIO, N. A era dos direitos. Rio de Janeiro: Campus, 1992.

BORDAS, F. C.; RAYMUNDO, M. M, GOLDIM, J. R. Aspectos bioéticos e jurídicos do transexualismo. Rev HCPA, v. 20., n. 2, p. 35-39, 2000.

BRASIL. Senado Federal. Constituição [da] República Federativa do Brasil. Brasília: Senado Federal, 1988.

. Lei no 10.406. Código Civil Brasileiro. Diário Oficial da Uniāo, 11 jan. 2002.

CARDOSO, F. L. Inversões do papel de gênero: drag queens, travestismo e transexualismo. Psicol Reflex Crit, v. 18, n. 3, p. 421-430, 2005.

CASTEL, P-H. Algumas reflexōes para estabelecer a cronologia do 'fenômeno transexual' (19101995). Revista Brasileira de História, v. 21, n. 41, 2001. Disponível em: http://www.scielo.br/ scielo.php?script=sci_arttext\&pid=S0102-01882001000200005\&lng=en\&nrm=iso\&tlng=pt Acesso em: 13 jun 2005. 
CASTEL, P-H. La métamorphose impensable. Essai sur le transsexualisme et l' identité personnelle. Paris, Gallimard, 2003.

. Transsexualisme. 2005. Disponível em: http://pierrehenri.castel.free.fr/Articles/ transexualisme.htm Acesso em: 16 jun 2005.

CHAVES, A. Castração. Esterilização. "Mudança" artificial de sexo. Rev Info Legislativa, v. 18, n. 69, p. 261-272, 1981.

CHILAND, C. Cambiar de sexo. Madrid: Asociación Psiconalítica de Madrid, 1999.

CONSELHO FEDERAL DE MEDICINA. Processo Consulta CFM n. 0617/90. PC/CFM/ n. ${ }^{\circ 11 / 1991 . ~ D i s p o n i ́ v e l ~ e m: ~ h t t p: / / w w w . p o r t a l m e d i c o . o r g . b r ~ A c e s s o ~ e m: ~} 06$ mar. 2006.

. Resolução CFM no. 1.482/97. Dispõe sobre a cirurgia de transgenitalismo. Conselho Federal de Medicina, 1997. Disponível em: http://www.portalmedico.org.br Acesso em: 06 mar 2006.

. Resolução CFM n.o 1.652/2002. Dispõe sobre a cirurgia de transgenitalismo e revoga a Resolução CFM no 1.482/97. Conselho Federal de Medicina, 2002. Disponível em: http:// www.portalmedico.org.br Acesso em: 06 mar 2006.

COOK, R.J.; DICKENS, B. M.; FATHALLA, M. F. Saúde reprodutiva e direitos humanos: integrando medicina, ética e direito. Rio de Janeiro: CEPIA, 2004.

DALLARI, D. A. Liberdade para morrer. Saúde Dir. Hum, v. 2, n. 2, p. 11-14, 2005.

FRIGNET, H. O transexualismo. Rio de Janeiro: Companhia de Freud; 2000.

HOTTOIS, G. Transsexualisme. In: HOTTOIS, G.; MISSA, J-N. (orgs.). Nouvelle encyclopédie de bioéthique. Bruxelles : De Boeck, 2001. p. 848-849.

KONDER C.N. O consentimento no Biodireito: os casos dos transexuais e dos wannabes. Revista Trimestral de Direito Civil, v. 16, p. 1541-1571, 2003.

KOTTOW M. Enseñando las paradojas de la autonomia. Rev Bras Educ Med, v. 24, n. 3, p. 40-45, 2000.

LEIVAS, P. G. C. A rejeição da conduta homossexual por John Finnis. In: RIOS, R. R. (org.). Em defesa dos direitos sexuais. Porto Alegre: Livraria do Advogado, 2007.

MORAES, M. C. B. O conceito de dignidade humana: substrato axiológico e conteúdo normativo. In: SARLET, Ingo W. (org.). Constituição, Direitos Fundamentais e Direito Privado. Porto Alegre: Livraria do Advogado, 2003. p. 105-149.

PERES, A. P. A. B. Transexualismo: o direito a uma nova identidade sexual. Rio de Janeiro: Renovar, 2001.

REY, L. Dicionário de termos técnicos de medicina e saúde. Rio de Janeiro: Guanabara Koogan, 2003.

RICOEUR, P. O si-mesmo como um outro. Campinas: Papirus, 1991. 
RODOTÀ, S. Nuovi diritti. L' età dei diritti. Disponível em: http://www.cgil.it/org.diritti/bioetica/ bobbio.htm. Acesso em: 16 jun 2005.

. Transformações do corpo. Revista Trimestral de Direito Civil, v. 19, n. 5, p. 91-107, 2004.

SAADEH, A. Transtorno de Identidade Sexual: um estudo psicopatológico de transexualismo masculino e feminino. Tese (Doutorado em Medicina) - Faculdade de Medicina, Universidade de São Paulo, São Paulo, 2004.

SCHNEEWIND, J. B. A invenção da autonomia: uma história da filosofia moral moderna. São Leopoldo: Editora Unisinos, 2005 (Coleção Ideias).

SCHRAMM, F. R. A autonomia difícil. Rev Bras Bioética, v. 6, n. 1, p. 35-48, 1998.

. Paradigma Biotecnocientífico e Paradigma Bioético. In: ODA, L. M. (org.). Biosafety of transgenic organisms in human health products. Rio de Janeiro: Fiocruz, 1996. p. 109-127.

SEGRE, M. Reflections on bioethics: consolidation of the principle of autonomy and legal aspects (Reflexões em bioética: consolidação do princípio da autonomia e aspectos legais) Cadernos de Saúde Pública, v. 15, n. S1, p. 91-98, 1999.

SOUZA, C. A. C. Transexualismo: diagnóstico, tratamento e alteração jurídica da identidade genérica. Psychiatry on Line Brazil, 2004. Disponível em: http:www.polbr.med.br/arquivo/ artigo0404.htm Acesso em: 11 jan 2007.

SUPERIOR TRIBUNAL FEDERAL. Agravo Regimental n. ${ }^{\circ}$ 82.517, de 28 abr 1981. Disponível em: www.stf.gov.br Acesso em: 08 nov. 2006.

VENTURA, M. Transexualismo e respeito à autonomia: um estudo bioético dos aspectos jurídicos e de saúde da "terapia para mudança de sexo". Dissertação (Mestrado em Saúde Pública) - Escola Nacional de Saúde Pública Sergio Arouca, Fundação Oswaldo Cruz, 2007. 135 f.

VIEIRA, T. R. Aspectos psicológicos, médicos e jurídicos do transexualismo. Psicol Info, v. 4, n. 4, 2000. Disponível em: http://editora.metodista.br/Psicologo1/psi05.pdf Acesso em: maio 2005.

VILLELA, W. V.; ARILHA, M. Sexualidade, gênero e direitos sexuais e reprodutivos. In: BERQUÓ, E. Sexo \& Vida: panorama da saúde reprodutiva no Brasil. Campinas: Unicamp, 2003. p. 95-145.

ZAMBRANO, E. Trocando os documentos: um estudo antropológico sobre a cirurgia de troca de sexo. Dissertação(Mestrado) - Instituto de Filosofia e Ciências Humanas, Universidade Federal do Rio Grande do Sul, Porto Alegre, 2003. 


\section{Notas}

${ }^{1}$ Entende-se por "atos de disposição" a possibilidade jurídica de a pessoa dispor livremente de algo, como um bem imóvel ou imóvel. Atos de disposição do corpo estão relacionados à possibilidade de a pessoa autorizar livremente que se realizam intervençôes médicas em seu corpo, como retirada de órgãos, amputações, e outras.

${ }^{2}$ A recomendação geral clínica é que sendo identificado qualquer distúrbio morfológico da diferenciação sexual, como nos casos dos hermafroditas, este deve ser corrigido através de intervenção cirúrgica reparadora, buscando adequar o sexo mais viável funcionalmente para a pessoa, antes dos dois anos de idade (REY, 2003). O desenvolvimento normal ou adequado da identidade sexual da pessoa está relacionado à conformação de sua genitália externa a um determinado sexo.

${ }^{3}$ No ano de 2001, o Ministério Público Federal do Rio Grande do Sul interpôs ação civil pública, motivada por uma ONG que defendia os direitos de LGBT requerendo a inclusão, no SUS, dos procedimentos transexualizadores. O Tribunal Federal de Recursos do Rio Grande do Sul determinou a inclusão, e a Advocacia Geral da União recorreu da decisão para o Supremo Tribunal Federal (STF), que entendeu que o Judiciário não deve determinar a inclusão de procedimentos médicos no SUS de forma genérica, pois isso implicaria aumento de despesas e alteração do orçamento federal do setor, com possíveis prejuízos para outras ações e programas de saúde. Mas reconheceu como legal a demanda dos/as transexuais para o acesso à terapia hormonal e cirúrgica na rede pública de saúde, e que o Judiciário deve apreciar, caso a caso, a necessidade do/a requerente de ter acesso ao tratamento gratuito no SUS. (Apelação Cível 2001.71.00.026279-9/RS. TRF da 4a Região 2001; 27 nov. www.trf4.gov.br). 


\section{Limits and possibilities to the exercise on autonomy in therapeutic practices of physical modification and sexual identity alteration}

According to current Brazilian health authority policies, one's access to physical modifications to have his/her sexual identity altered is dependent upon an established psychiatric diagnosis of transsexualism gender or sexual identity disorder - in addition to two years of psychiatric evaluations, in order to have it come to fruition. The discomfort with his/her sexual anatomy and the desire to have his/her genitalia modified is the defining criteria to the diagnosis of transsexualism. Sex reassignment surgery is considered to be the last step of such a treatment, and it is viewed by the Judiciary as a necessary condition to effect change in the legal sexual identity status of the transsexual person. This paper argues the moral conflict between transsexual issues and current health policies related to one's exercise on autonomy with regard to therapeutic practices. Hence, Bioethics tools are applied to the discussion, due to the result obtained from an analysis of the arguments made by the health authorities and judicial systems, on the subject, through articles, documents, and Brazilian court decisions. Regarding therapeutic and legal access, some advances have been made. However, notwithstanding, limitations and restrictions still being imposed regarding the exercise of the autonomy of the transsexual individual, might have a negative impact on the health and legal rights of those not acknowledged by the current norms as "true transsexuals". The rights of the transsexual individual to a comprehensive healthcare assistance system, including sexually related health issues, as well as the right to the free development of his/her personality are infringed, at the very moment when the patient's autonomy is not duly safeguarded by current health policies, thus making human rights look more like a duty, to which the person must adapt to as the dominant sexual morality.

> Key words: transsexualism; bioethics; medicine; human rights; individual autonomy. 